\title{
Comparing the impact of older age on outcome in chronic kidney disease of different etiologies: a prospective cohort study
}

\author{
Maharajan Raman $^{1,2} \cdot$ Darren Green $^{1,2}\left(\mathbb{D}^{\circ} \cdot\right.$ Rachel J. Middleton $^{1,2} \cdot$ Philip A. Kalra ${ }^{1,2}$
}

Received: 17 May 2018 / Accepted: 22 August 2018 / Published online: 5 September 2018

(c) The Author(s) 2018

\begin{abstract}
Background In older patients with chronic kidney disease (CKD), the risk of progression to end stage renal disease and cardiovascular death both differ compared to younger patients. This likely reflects differences in case mix and co-morbid burdens. We sought to establish the extent to which age itself is an independent biomarker of adverse outcome in CKD.

Methods This was an analysis of the Salford Kidney Study, a prospective, longitudinal, observational study of 2,667 patients with eGFR $<60 \mathrm{ml} / \mathrm{min} / 1.73 \mathrm{~m}^{2}$. Patients were divided into four age groups $(<55,55-65,65-75$ and $>75$ years). Within group adjusted hazard ratios for death in older compared to younger patients were calculated for different primary renal diseases. A competing risk model of death and renal replacement therapy (RRT) as outcomes was performed.

Results The median age of the cohort was 67.1 years [interquartile range (IQR): 55.6-75.3] and median eGFR $30.8 \mathrm{ml} /$ $\mathrm{min} / 1.73 \mathrm{~m}^{2}$ (IQR: 20.6-43.2). Follow up was $3.5 \pm 2.9$ years. Overall, the adjusted HR for death in patients aged $>75$ years compared to those $<55$ years was 4.4 (95\% CI 3.4-5.9), $\mathrm{p}<0.001$. The HR for death differed between primary renal diseases and CKD stages. In diabetic nephropathy, the HR was $3.0(1.8-5.3, \mathrm{p}<0.001)$, in glomerulonephritis the HR was 12.2 $(5.6-25.5, \mathrm{p}<0.001)$. The cumulative incidence of RRT was $<0.1$ at 10 years for patients $>75$ years, compared with 0.50 in those $<55$ years. Death was more likely at 20 months in those aged 75 years or older $(0.17)$ than at 10 years in those aged $<55$ years $(0.10)$.

Conclusion This study demonstrates that the risk associated with older age shows significant variability between primary renal diseases. This is whilst acknowledging that observational studies carry the risk of hidden bias not adjusted for in the statistical model.
\end{abstract}

Keywords CKD $\cdot$ Older age $\cdot$ Survival

\section{Introduction}

The general population is ageing [1], and the prevalence of stages 3 to $5 \mathrm{CKD}$ amongst adults is increasing [2]. The risk of developing CKD increases with age. The NEOERICA project showed that among 65,126 subjects aged 18

Electronic supplementary material The online version of this article (https://doi.org/10.1007/s40620-018-0529-8) contains supplementary material, which is available to authorized users.

Darren Green

darrengreen@doctors.org.uk

1 Vascular Research Group, Department of Renal Medicine, Salford Royal NHS Foundation Trust, Stott Lane, Salford M6 8HD, UK

2 Faculty of Biology, Medicine and Health, University of Manchester, Manchester, UK to $>85$ years, the proportion of subjects with CKD stages 3 to 5 was $6.9 \%$ between ages $55-64$ years and $44.7 \%$ in people $>85$ years [3]. CKD in older patients can be unrecognized but also may be inappropriately managed, for example with a failure to address secondary preventive measures [4]. It is well known that subjects with CKD have a high cardiovascular risk $[5,6]$. Older CKD patients differ compared to younger patients in that their risk of progression to end stage renal disease (ESRD) is lower than the risk of cardiovascular death $[7,8]$, whereas the opposite is true in younger patients. Older patients also demonstrate slower CKD disease progression. This is likely to reflect the different case mix of primary renal diseases found across different age groups, and the greater co-morbid burden of advancing age [9-11].

We sought to establish the extent to which age itself is a biomarker of adverse outcome in CKD, independent of these factors, and to determine whether any apparent increased 
risk associated with older age differs between primary renal diseases, and between different CKD stages at presentation. This would provide nephrologists with more individualized risk stratification information based on age, eGFR and primary renal disease. To achieve this, the primary aim of the study was to determine the relative risk of death in older compared to young patients with CKD, specifically whether the greater risk of death associated with older age varies between primary renal diseases. The secondary aim was to explore the likelihood of older versus younger patients reaching end stage kidney disease in the context of an increasing risk of death with older age, using a competitive risk approach.

\section{Methods}

This was a sub-study of the Salford Kidney Study, a single centre, prospectively collected, observational study of outcomes in Chronic Kidney Disease in the United Kingdom, recruiting since March 2002. Patients who are referred to the Nephrology Secondary Care outpatient clinic at Salford Royal NHS Foundation Trust, or admitted to the Nephrology inpatient ward, are approached for inclusion in the study, and are enrolled if written, informed consent is gained. The inclusion criteria are: age $\geq 18$ years at the time of consent; eGFR $<60 \mathrm{~mL} / \mathrm{min} / 1.73 \mathrm{~m}^{2}$ (calculated using the creatininebased 4 variable MDRD equation); and able to give written, informed consent for participation. Patients with acute kidney injury, functioning renal transplant, or already established on dialysis are enrolled into SKS but were excluded from this analysis. The study complies with the declaration of Helsinki and local ethical approval has been obtained (current REC reference 15/NW/0818).

Patients undergo an annual review including detailed clinical phenotyping and event reporting. Phenotype and outcome data are collected from patient self-reporting, Hospital Electronic Patient Records, primary care records, and mortality data from the Office for National Statistics. Patients with a previous history of myocardial infarction or coronary artery revascularization (including bypass graft), or a history of medically managed angina, were classified as having coronary artery disease (CAD). Patients with previous history of ischemic or haemorrhagic stroke, or transient ischemic attack (TIA), were classified as having cerebrovascular disease (CVD). Patients with symptoms of claudication, presence of distal ischemic ulcers, amputation due to distal ischemia, or who had undergone a peripheral arterial revascularization procedure, were classified as having peripheral vascular disease (PVD). Patients with clinical diagnosis of heart failure, with no other alternative explanation for the patient's symptoms of breathlessness, or an echocardiogram showing evidence of either left ventricular ejection fraction (LVEF) $<50 \%$ or meeting diastolic dysfunction criteria, were classified as having congestive cardiac failure $(\mathrm{CCF})$.

The study population of 2667 patients was divided in to four age groups: $<55$ years, 55-65 years, $65-75$ years and $>75$ years. Baseline demographic data, primary renal disease, co-morbidities, medications, and laboratory data were compared between patients of different ages. The distribution of variable was assessed using the Shapiro-Wilk test. Normally distributed variables were reported as mean \pm standard deviation (SD), skewed variables were reported as median with interquartile range (IQR), and categorical variables were reported as percentages. To assess the difference in baseline characteristics between different age groups, analysis of variance (ANOVA) or Kruskal-Wallis (depending on the distribution of the variable) and Chi square tests, were used for continuous and categorical variables, respectively.

We calculated hazard rations for death in older patients compared to the reference group of patients aged $<55$ years in the entire study population, and in individual primary renal diseases. Analysis was performed using a multi-variate Cox proportional hazard model, with variables which were statistically significantly associated with outcome on univariate analysis included alongside age group. Analysis of renal replacement therapy and death in a competitive risk approach was performed using the "cmprsk" package within $\mathrm{R}[12,13]$.

Follow up started on the date of first study visit, through to death (all cause) or 31st May 2015. In the competitive risk model, RRT was defined as the initiation of dialysis (either peritoneal or haemodialysis), or transplantation. Patients for conservative care, not RRT were censored when eGFR was first $<10 \mathrm{~mL} / \mathrm{min} / 1.73 \mathrm{~m}^{2}$.

Specific primary renal diseases chosen for sub-group analysis were hypertension, atherosclerotic renovascular disease (ARVD), diabetes and glomerulonephritis (GN). A pragmatic approach to categorisation was used, in that primary diagnoses were often presumed rather than biopsy proven and only one diagnosis was assigned to each patient.

\section{Results}

2667 patients were included in the analysis. The median age of the cohort was 67.1 years [interquartile range (IQR): 55.6-75.3] and median eGFR was $30.8 \mathrm{ml} / \mathrm{min} / 1.73 \mathrm{~m}^{2}$ (IQR: 20.6-43.2). 62\% were men. The cohort divided into different age groups as follows: $24 \%(n=641)$ were aged $<55$ years; $19 \%(\mathrm{n}=504)$ were aged $55-65$ years; $30 \%$ $(\mathrm{n}=812)$ were aged $65-75$ years, and $27 \%(\mathrm{n}=710)$ were aged $>75$ years. 


\section{Baseline characteristics}

A detailed outline of baseline characteristics comparing different age groups is found in Table 1. Over the age of 75 years, hypertension and atherosclerotic renovascular disease (ARVD) were the commonest causes of CKD (20\% and $21 \%$ respectively). In the youngest age group ( $<55$ years), glomerulonephritis (GN) and polycystic kidney disease (ADPKD) were the commonest causes of CKD (26\% and $12 \%$ respectively). Hypertension and ARVD accounted for just $8 \%$ of CKD in this younger group. The cause of GN differed between age groups. The most common cause of GN in patients under 55 years was IgA nephropathy (45\%) followed by FSGS (25\%), and membranous disease (12\%).

Table 1 Baseline characteristics, overall and comparing different age groups

\begin{tabular}{|c|c|c|c|c|c|}
\hline & Overall $(n=2667)$ & $<55$ years $(\mathrm{n}=641)$ & $55-65$ years $(n=504)$ & $65-75$ years $(n=812)$ & $>75$ years $(n=710)$ \\
\hline Age (years)* & $67.1(55.6-75.3)$ & $45.5(37.8-50.3)$ & $60.7(58.3-63.1)$ & $70.2(67.5-72.3)$ & $79.5(77.1-82.5)$ \\
\hline Mean SBP* & $138(124-152)$ & $130(119-142)$ & $138(123-150)$ & $140(128-155)$ & $142(127-157)$ \\
\hline Male\% & 62.1 & 56.3 & 64.1 & 64 & 64.1 \\
\hline Smoker\% & 66.7 & 54 & 67.3 & 72.3 & 71.4 \\
\hline \multicolumn{6}{|l|}{ Primary renal disease } \\
\hline Hypertension $\%$ & 12.8 & 5.1 & 10.1 & 13.9 & 20.3 \\
\hline ARVD $\%$ & 12.2 & 3 & 7.3 & 14.8 & 21.1 \\
\hline Diabetes $\%$ & 16.8 & 14.7 & 20.2 & 20.1 & 12.7 \\
\hline Obstruction $\%$ & 1.4 & 0.8 & 1.4 & 1.4 & 2.1 \\
\hline GN\% & 15.9 & 25.7 & 20.6 & 12.6 & 7.6 \\
\hline Pyelonephritis\% & 5.8 & 12 & 4.8 & 4.1 & 3 \\
\hline ADPKD $\%$ & 5.1 & 12.6 & 5 & 2.6 & 1.1 \\
\hline Other $\%$ & 15.7 & 17.5 & 18.1 & 16.1 & 12 \\
\hline Unknown\% & 14.1 & 8.3 & 12.5 & 14.4 & 20.1 \\
\hline \multicolumn{6}{|l|}{ Comorbidities } \\
\hline CAD \% & 28.6 & 7.2 & 23.2 & 36.3 & 43.5 \\
\hline PVD $\%$ & 21.6 & 11.5 & 22.4 & 26.2 & 25 \\
\hline CVD\% & 14.4 & 4.8 & 11.4 & 19.7 & 20.3 \\
\hline $\mathrm{CCF} \%$ & 19.4 & 8 & 14.3 & 23.7 & 28.6 \\
\hline Diabetes $\%$ & 32.4 & 19.2 & 37.2 & 39 & 33.2 \\
\hline \multicolumn{6}{|l|}{ Medication } \\
\hline $\mathrm{N}$ anti-HT* & $2(1-3)$ & $2(1-3)$ & $2(1-3)$ & $2(2-3)$ & $2(2-3)$ \\
\hline RAS-i\% & 62.1 & 72.5 & 65.3 & 62.2 & 53.7 \\
\hline ESA $\%$ & 13.7 & 11.7 & 11.7 & 14.2 & 16.6 \\
\hline Statin $\%$ & 60.2 & 44.6 & 62.1 & 70.2 & 61.6 \\
\hline Beta blocker\% & 38.1 & 31.8 & 36.5 & 42.3 & 40 \\
\hline ССВ $\%$ & 53 & 45 & 56.4 & 56.5 & 54.2 \\
\hline \multicolumn{6}{|l|}{ Laboratory } \\
\hline eGFR* & $30.8(20.6-43.2)$ & $34.3(21.7-48.4)$ & $33.1(21.2-46.9)$ & $31.7(20.8-41.8)$ & $27.5(19.6-37.1)$ \\
\hline Haemoglobin $(g / l)^{\mathfrak{E}}$ & $122 \pm 21$ & $125 \pm 19$ & $124 \pm 17$ & $123 \pm 16$ & $120 \pm 16$ \\
\hline uPCR $(\mathrm{g} / \mathrm{mmol})^{*}$ & $26(11-84)$ & $46(15-139)$ & $27(11-85)$ & $20(10-65)$ & $21(10-56)$ \\
\hline PTH (ng/l)* & $60(33-110)$ & $56(31-111)$ & $57(34-101)$ & $61(37-105.7)$ & $83(48-132)$ \\
\hline Albumin $(g / l)^{*}$ & $42(39-45)$ & $43(39-45)$ & $43(40-45)$ & $42(39-44)$ & $42(39-44)$ \\
\hline Phosphate $(\mathrm{mmol} / \mathrm{l})^{*}$ & $1.12(0.98-1.29)$ & $1.15(0.97-1.33)$ & $1.11(0.96-1.31)$ & $1.11(0.97-1.28)$ & $1.13(1.0-1.26)$ \\
\hline Calcium $(\mathrm{mmol} / \mathrm{l})^{*}$ & $2.28(2.2-2.37)$ & $2.27(2.18-2.36)$ & $2.27(2.18-2.36)$ & $2.28(2.2-2.37)$ & $2.28(2.19-2.37)$ \\
\hline Cholesterol* & $4.5(3.7-5.3)$ & $4.9(4.1-5.8)$ & $4.4(3.7-5.4)$ & $4.3(3.6-5.1)$ & $4.2(3.5-4.9)$ \\
\hline
\end{tabular}

$S B P$ systolic blood pressure, $A R V D$ atherosclerotic renovascular disease, GN Glomerulonephritis, $A D P K D$ autosomal dominant polycystic kidney disease, $C A D$ coronary artery disease, $P V D$ peripheral vascular disease, $C V D$ cerebrovascular disease, $C C F$ congestive cardiac failure, $N$ anti-HT number of anti-hypertensive medications, $R A S-I$ renin-angiotensin system inhibitors, ESA erythropoietin stimulating agent, $C C B$ calcium channel blocker, $e G F R$ estimated glomerular filtration rate, $u P C R$ urine protein creatinine ratio, $P T H$ parathyroid hormone

*Median (interquartile range)

${ }^{£}$ Mean \pm standard deviation 
The most common cause in patients aged 55-65 years was also IgA nephropathy (35\%) followed by FSGS (22\%) and membranous disease (18\%). In patients aged $65-75$ years, IgA nephropathy (41\%) and membranous disease $(20 \%)$ remained very common but ANCA mediated vasculitis was more frequently seen than FSGS (15\% versus $13 \%$ ). In patients aged $>75$ years, membranous disease was more common (33\%) than IgA nephropathy (31\%). FSGS was seen in $15 \%$ of GN patients $>75$ years, and ANCA vasculitis $8 \%$.

With increasing age, there was significant accumulation of co-morbidities. Comparing the age groups $>75$ years and $<55$ years, $43.5 \%$ versus $7.2 \%$ had coronary artery disease (CAD), $25 \%$ versus $11.5 \%$ had peripheral vascular disease (PVD), $20.3 \%$ versus $4.8 \%$ had cerebrovascular disease (CVD), 28.6 versus $8 \%$ had congestive cardiac failure (CCF), and $33.3 \%$ versus $19.2 \%$ had diabetes.

Only $53.7 \%$ of patients $>75$ years were prescribed renin angiotensin system inhibitors (RAS-i), compared to $72.5 \%$ of the patients aged $<55$ years. Details of this and other prescribed medication are shown in Table 1.

Table 1 also details baseline laboratory parameters between age groups. The median eGFR for the $>75$ years group was the lowest, $27.5 \mathrm{ml} / \mathrm{min} / 1.73 \mathrm{~m}^{2}$ (IQR: 19.6-37.1). This compared with $34.3 \mathrm{ml} / \mathrm{min} / 1.73 \mathrm{~m}^{2}$ (IQR: $21.7-48.4)$ in the $<55$ years group. All of the parameters in Table 1 (including demographics, co-morbidities, primary renal disease, medication, laboratory parameters) differed between age groups at a level $\mathrm{p}<0.01$, except for calcium $(\mathrm{p}=0.144)$.

Table 2 Events rates per 1000 patient years for all-cause mortality and commencing renal replacement therapy (RRT), divided according to age

\begin{tabular}{llcl}
\hline Age group (years) & Total number & $\begin{array}{c}\text { Mortality } \\
(\mathrm{n}=897)\end{array}$ & RRT $(\mathrm{n}=474)$ \\
\hline$<55$ & 641 & 29.9 & 86.8 \\
$55-65$ & 504 & 53.2 & 50.8 \\
$65-75$ & 812 & 120.6 & 40.8 \\
$>75$ & 710 & 175.1 & 22.1 \\
\hline
\end{tabular}

The mean follow up of the cohort was $3.5 \pm 2.9$ years. During follow up, 34\% $(\mathrm{n}=897)$ of the cohort had died and $18 \%(\mathrm{n}=474)$ had begun RRT. Mortality per 1000 patientyears was the highest in the age group $>75$ years $(175.1)$ and lowest in the age group $<55$ years (29.9). Coupled with this, the number of patients commencing RRT per 1000 patient-years was lowest in the age group $>75$ years (22.1) and highest in the age group $<55$ years (86.8). Full details of event rates per 1000 patient years for death and ESRD for the whole population and each primary disease diagnosis are found in Table 2.

\section{Survival analysis}

Within the whole study population, the factors which were significantly associated with mortality on univariate Cox proportional hazards regression analysis were male gender, SBP, smoking, baseline eGFR, CAD, CVD, PVD, CCF and diabetes. These parameters were entered into a multivariate model along with age group, with age $<55$ years as the reference group. The adjusted hazard ratio (HR) for death in the age group 55-65 years compared to age $<55$ years was $1.41(95 \%$ CI 1.03-1.92), $\mathrm{p}=0.030$, in the age group $65-75$ years was $2.83(2.15-3.72), \mathrm{p}<0.001$ and in the age group $>75$ years was 4.46 (3.39-5.87), $\mathrm{p}<0.001$.

In a multivariate Cox model for all-cause mortality in specific primary renal diseases (Table 3), the HR for death increased with age in all diseases. However, the HR for death in patients aged $>75$ years (relative to $<55$ years) varied markedly between diseases. For patients with glomerulonephritis, the HR for death in those aged $>75$ years was 12.2 (95\% CI 5.6-26.5), p < 0.001, compared to the reference group. For hypertension the HR was $10.1(95 \%$ CI 2.9-34.1), $\mathrm{p}=0.001$. In ARVD and diabetes, the HR were much lower [ARVD HR 3.4 (95\% CI 1.2-9.5) $\mathrm{p}=0.02$, diabetes HR $3.0(95 \%$ CI 1.8-5.3) p <0.001].

Table 3 A comparison of adjusted hazard ratios for death in older compared to younger patients across different primary diseases

\begin{tabular}{|c|c|c|c|c|c|c|c|c|c|c|c|c|c|c|c|c|}
\hline \multirow[b]{2}{*}{ Age } & \multicolumn{4}{|c|}{ Hypertension } & \multicolumn{4}{|c|}{ ARVD } & \multicolumn{4}{|c|}{ Diabetes } & \multicolumn{4}{|c|}{ Glomerulonephritis } \\
\hline & $\mathrm{N}$ & HR & $95 \% \mathrm{CI}$ & $\mathrm{P}$ & $\mathrm{N}$ & HR & $95 \% \mathrm{CI}$ & $\mathrm{P}$ & $\mathrm{N}$ & HR & $95 \% \mathrm{CI}$ & $\mathrm{P}$ & $\mathrm{N}$ & HR & $95 \% \mathrm{CI}$ & $\mathrm{P}$ \\
\hline \multicolumn{17}{|l|}{ Death } \\
\hline$<55^{*}$ & 31 & 1.00 & & & 19 & 1.00 & & & 92 & 1.00 & & & 161 & 1.00 & & \\
\hline $55-65$ & 51 & 0.8 & $0.1-3.9$ & 0.751 & 35 & 2.2 & $0.7-6.8$ & 0.161 & 99 & 1.1 & $0.6-1.9$ & 0.738 & 100 & 1.5 & $0.6-3.4$ & 0.335 \\
\hline $65-75$ & 109 & 5.7 & $1.7-19.8$ & 0.006 & 116 & 3.3 & $1.2-9.1$ & 0.024 & 160 & 1.7 & $1.0-2.8$ & 0.047 & 100 & 4.9 & 2.4-9.9 & $<0.001$ \\
\hline$>75$ & 140 & 10.1 & $2.9-34.1$ & $<0.001$ & 140 & 3.4 & $1.2-9.5$ & 0.020 & 83 & 3.0 & $1.8-5.3$ & $<0.001$ & 51 & 12.2 & $5.6-26.5$ & $<0.001$ \\
\hline
\end{tabular}

$R R T$ renal replacement therapy, $A R V D$ atherosclerotic renovascular disease, $N$ number, $H R$ hazard ratio, $C I$ confidence interval 
Table 4 Cumulative incidence of death and renal replacement therapy (RRT) at 5 years follow up for patients with chronic kidney disease in a competing risk model

\begin{tabular}{llllll}
\hline Age (years) & All & GN & DM & HT & ARVD \\
\hline Death & & & & & \\
Under 55 & 0.05 & 0.05 & 0.07 & 0.00 & 0.06 \\
55 to 64 & 0.15 & 0.08 & 0.21 & 0.08 & 0.32 \\
65 to 74 & 0.34 & 0.32 & 0.38 & 0.28 & 0.51 \\
75 plus & 0.51 & 0.43 & 0.70 & 0.50 & 0.52 \\
RRT & & & & & \\
Under 55 & 0.36 & 0.28 & 0.50 & 0.37 & 0.52 \\
55 to 64 & 0.20 & 0.22 & 0.27 & 0.20 & 0.08 \\
65 to 74 & 0.16 & 0.17 & 0.22 & 0.11 & 0.07 \\
75 plus & 0.08 & 0.20 & 0.06 & 0.06 & 0.06 \\
\hline
\end{tabular}

Results are divided by primary renal disease and age on presentation All all diagnoses, $G N$ glomerulonephritis, $D M$ diabetic nephropathy, $H T$ hypertension, $A R V D$ atherosclerotic renovascular disease

\section{Competitive risk analysis of death and renal replacement therapy}

There was a striking difference in incidence of RRT between younger and older patients. For those aged $<55$ years, the cumulative incidence at 5 years was 0.36 , and 0.50 at ten years. By contrast, RRT was uncommon in older patients ( 0.08 at 5 years, and 0.09 at 10 years for age 75 years or more).

Death was uncommon in the youngest age group. The cumulative incidence was 0.05 at 5 years and 0.10 at 10 years. In the age group 55-64 years, RRT remained more frequent as an outcome that death $(0.20$ versus 0.15 at 5 years, 0.33 versus 0.24 at 10 years). In the two older age groups, however, death was more likely than RRT.

The cumulative incidence for death at 5 years follow up in the age groups $65-74$ and 75 or more years was 0.34 and 0.51 respectively. At 10 years the cumulative incidences were 0.57 and 0.83 respectively for these groups. Indeed, death was more common by 20 months in those aged 75 years or older $(0.17)$ than at 10 years in those aged $<55$ years $(0.10)$.

In analysis of primary disease specific patterns of outcome, the likelihood of RRT was much higher for younger than older patients in diabetic nephropathy, hypertension, and ARVD, following similar patterns to that seen in the whole population analysis. The glomerulonephritis group followed a different pattern with the cumulative incidence of RRT being broadly similar across all age groups. For those under 55 years with glomerulonephritis, the cumulative incidence of RRT at 5 years was 0.28 , for age 55-64 years was 0.22 , for age $65-74$ years was 0.17 , and for patients aged 75 years or older was 0.20 . Table 4 displays the likelihood of death and RRT at 5 years follow up in a competing risk model, divided by primary renal disease and age on presentation.

The likelihood of death was low in all diagnoses for the youngest patient group, the cumulative incidence at 5 years being no higher than 0.07 for any given diagnosis. Diabetic nephropathy was associated with the highest likelihood of death in all age groups above 55 years at 5 years follow up (cumulative incidence 0.21 for age 55-64 years, 0.38 for age 65-74 years, 0.70 for patients aged 75 years or older). Cumulative results for death and RRT as competitive risks for patients of different age groups are displayed in Fig. 1. Full details of risk for both end points at all time points up to 10 years for all diagnoses can be found in online table 1 .

The age group in which death became a cumulatively more likely outcome that RRT differed between primary diseases (Fig. 2). In the whole population, this occurred in the age group 65-74 years. For ARVD, death was more likely than RRT during follow up for all age groups above age 55 years. For glomerulonephritis patients, death was more likely as an end point in patients aged 65 years or older. For those aged 55-64 years, RRT was more likely than death at 5 years, but not at 10 years. In hypertension, death became more likely than RRT in the age 65 years or older group. For diabetes, death and RRT were equally likely at all points during follow up for those aged 55-64 years. Again, death became more likely than RRT at all stages of follow up in those aged 65 years or more on presentation.

\section{Discussion}

A key finding of his study is that the relative risk of death in older compared to younger CKD patients differs markedly between primary renal diseases. Older patients with glomerulonephritis have the highest adjusted risk for death compared to younger patients with the same diagnosis, and ARVD the lowest. Interestingly, the absolute mortality rate (events per 1000 patient years) is highest in the ARVD group. This likely reflects the significant impact of cardiovascular co-morbidities on outcomes. The marked variation in mortality between age groups in patients with GN very likely reflects that this is not an homogenous diagnostic population. The cause of GN was most likely to be membranous nephropathy in the oldest patients, compared with IgA nephropathy in all other age groups. Membranous nephropathy can carry a worse prognosis, particularly when associated with other diseases such as malignancy.

Alongside this finding, and as expected, older patients have a very low likelihood of reaching end stage renal disease compared to younger patients. The progression to renal failure due to diabetes in older people has been described before [14]. Hemmelgran et al. in a study of 10,184 community dwelling older people ( $>66$ years) showed an overall 

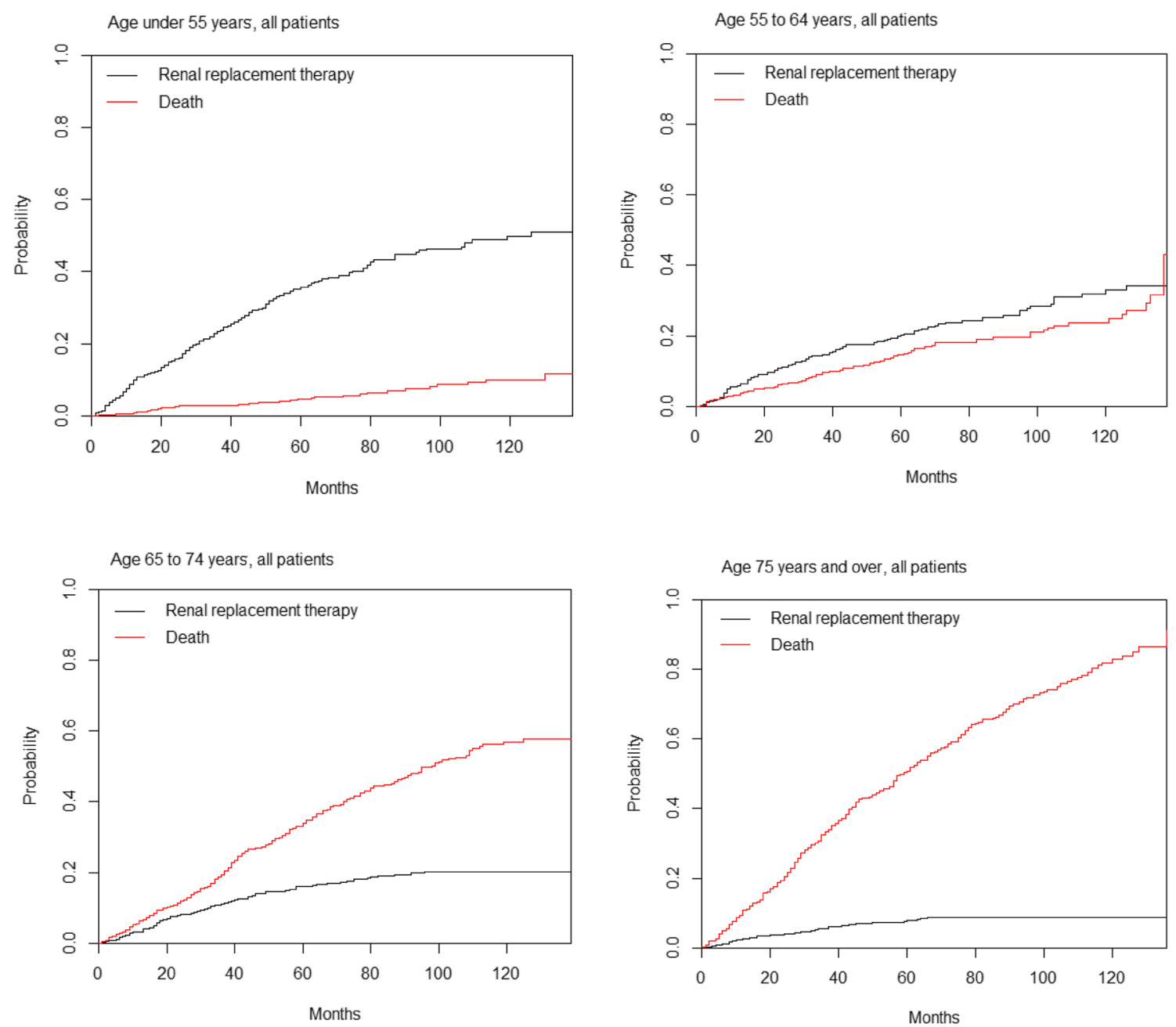

Fig. 1 Cumulative incidence of death and renal replacement therapy in a competitive risk model, in patients with chronic kidney disease divided into age groups

slow rate of decline in eGFR in this age group but also highlighted that subjects with diabetes had the fastest decline in the 2 year follow up period. The age adjusted decline in eGFR per year $(95 \% \mathrm{CI})$ for female and male diabetics was $2.1(1.8-2.5)$ and $2.7(2.3-3.1) \mathrm{ml} / \mathrm{min} / 1.73 \mathrm{~m}^{2} /$ year respectively, compared to women and men without diabetes, which were $0.8(0.6-1.0)$ and $1.4(1.2-1.6) \mathrm{ml} / \mathrm{min} / 1.73 \mathrm{~m}^{2} /$ year respectively [15]. This is low compared to the average decline of $7.5 \mathrm{ml} / \mathrm{min} /$ year in subjects with CKD described by the United States Renal Data System (USRDS) [16]. Although in our study we showed that diabetes had a low risk of progression to RRT we did not evaluate the rate of decline in eGFR which influences the progression to ESKD [17].

Several studies have shown the benefits of RAS inhibition in old people [18-20]. In our study, although the age group $>65$ years had the highest accumulation of cardiovascular co-morbidities, only half of them were prescribed
RAS inhibitor. This is perhaps due to the adverse events associated with these medications and the suboptimal use of secondary preventive measures in this age group described in literature [21-24].

In this prospective study of patients with CKD we have also demonstrated that, as age increases, the risk of ESKD is low compared to the risk of death. This inverse relationship between ESKD and death is consistent with previous studies [8, 25-28]. For example, O'Hare et al. in a study of 209,622 patients aged 18-100 years with CKD stages 3 to 5 , showed this inverse relationship between death and ESKD [24]. In this study the adjusted HR (95\% CI) for death in the age group 75-84 years, for CKD stages $3 b, 4$ and 5 was $2.6(1.8-3.7), 3.1(1.9-5.1)$ and $4.4(1.6-22.7)$ respectively, compared to the reference group, of patients aged 18 to 44 years. The HR (95\% CI) for ESKD for the same age groups, and also for CKD stages $3 \mathrm{~b}$ to 5 , were 0.1 $(0.08-0.1), 0.3(0.2-0.3)$ and $0.5(0.4-0.6)$ respectively. In 

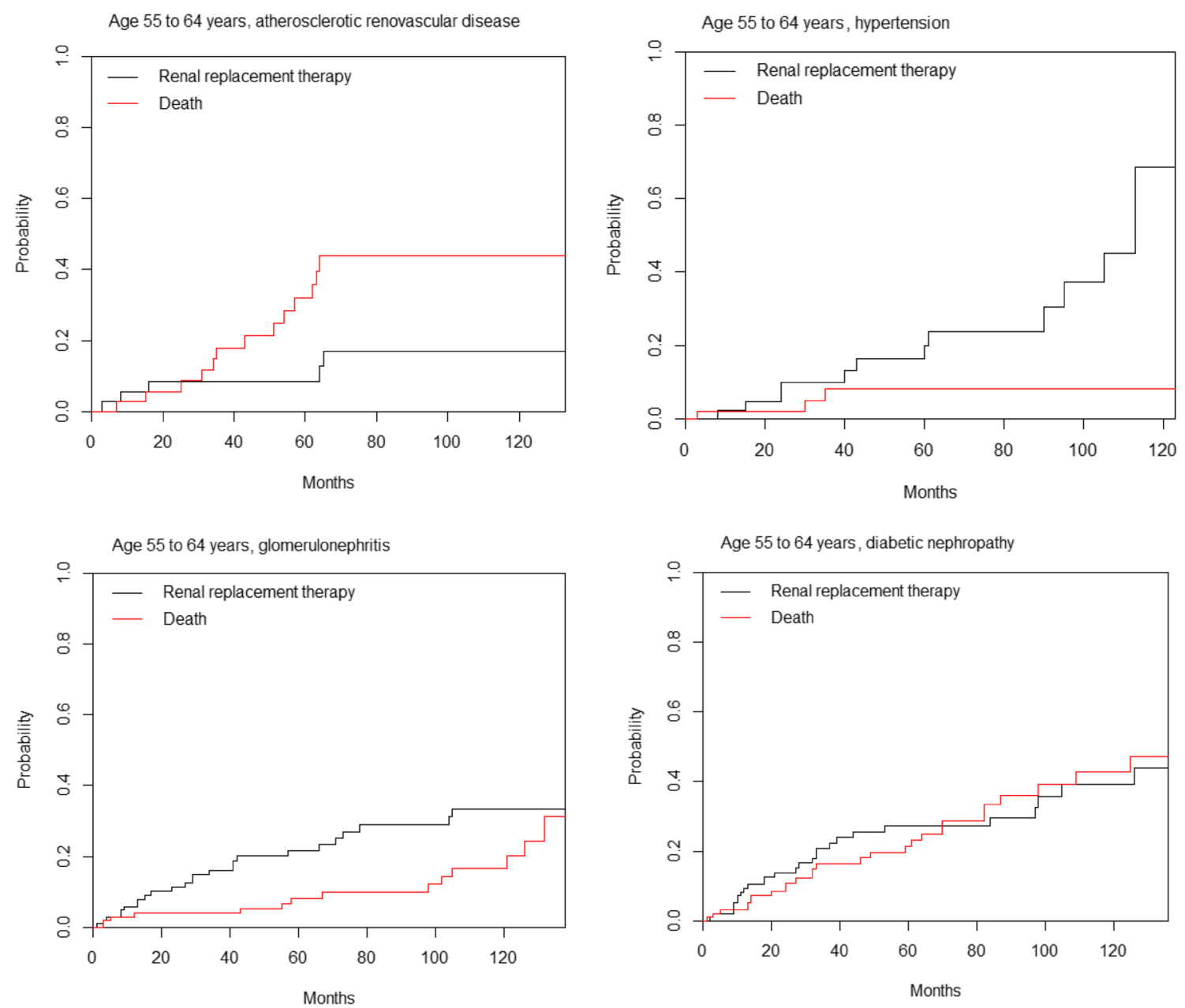

Fig. 2 A comparison of the cumulative likelihood of death and renal replacement therapy in different primary renal diseases, for patients aged 55-64 years

that study, only $3 \%$ of the study population was female and $86 \%$ were Caucasian. Our study has a greater proportion of female patients (38\%) but is also predominantly Caucasian in origin.

Manjunath et al. in their community based study of people aged $>65$ years, showed that all cause mortality increases with declining eGFR. The HR (95\% CI) for all-cause mortality in patients with eGFR between 15 and $59 \mathrm{ml} / \mathrm{min} / 1.73 \mathrm{~m}^{2}$, compared to an eGFR of 60 to $89 \mathrm{ml} /$ $\min / 1.73 \mathrm{~m}^{2}$, were $1.5(1.1-2.1)$ and $1.1(0.8-1.4)$ respectively [27]. De Nicola et al. showed that the risk of ESKD prevailed over death when eGFR was between 25 and $35 \mathrm{ml} /$ $\min / 1.73 \mathrm{~m}^{2}$ for the age group between 65 and 75 years and when the eGFR was less than $15 \mathrm{ml} / \mathrm{min} / 1.73 \mathrm{~m}^{2}$ for the age group $>85$ years [29]. This study also highlighted that proteinuria and increasing age are important risk factors for progressing to ESKD. In our study we did not evaluate the interaction of proteinuria and increasing age.
To conclude, the mix of comorbidities and prescribed medication, as well as the relative risk of death versus dialysis, is very different in older compared to younger CKD patients. Uniquely, this study demonstrates that the risk associated with older age shows significant variability between primary renal diseases. Glomerulonephritis demonstrates a worse outcome for older versus younger patients when compared to other diseases. Of note, eGFR was not independently associated with mortality in patients aged $<55$ years.

It is interesting to note that although the elderly ( $>65$ years) have the highest cardiovascular risk, only 50-60\% were prescribed renin angiotensin system inhibitors (RAS-i), compared to their younger counterparts. In this study we have also confirmed the inverse relationship between death and RRT with increasing age. Age specific risk profiling and management strategies may therefore be required given our ageing population. 
This study is not without limitations. The risk of progression to RRT was based on baseline eGFR at study inception and did not evaluate the rate of change in eGFR with time, which is known to influence the progression to ESKD. The risk of death and CKD progression may also be influenced by proteinuria, but proteinuria was not assessed in this study. In our analysis we have used the 4 variable MDRD equation in the calculation of eGFR as was standard in clinical practice during the study follow up period. However, this method of GFR estimation is not well validated in older people.

Funding The authors have no financial interests to declare. No external funding contributed to this work.

\section{Compliance with ethical standards}

Conflict of interest The authors have no potential conflicts of interest to declare.

Ethical approval All procedures performed in studies involving human participants were in accordance with the ethical standards of the institutional and/or national research committee and with the 1964 Helsinki declaration and its later amendments or comparable ethical standards. Local ethical approval has been obtained (current REC reference 15/ NW/0818).

Informed consent Written, informed consent was obtained from all participants in the study.

Open Access This article is distributed under the terms of the Creative Commons Attribution 4.0 International License (http://creativeco mmons.org/licenses/by/4.0/), which permits unrestricted use, distribution, and reproduction in any medium, provided you give appropriate credit to the original author(s) and the source, provide a link to the Creative Commons license, and indicate if changes were made.

\section{References}

1. Bengtsson T, Scott K (2010) The ageing population. Popul Ageing-A Threat to Welf. State? p. 2010

2. Kearns B, Gallagher H, de Lusignan S (2013) Predicting the prevalence of chronic kidney disease in the english population: a cross-sectional study. BMC Nephrol 14:49

3. Stevens PE, O'Donoghue DJ, de Lusignan S, Van Vlymen J, Klebe B, Middleton R, Hague N, New J, Farmer CKT (2007) Chronic kidney disease management in the United Kingdom: NEOERICA project results. Kidney Int 72(1):92-99

4. Rothberg MB, Kehoe ED, Courtemanche AL, Kenosi T, Pekow PS, Brennan MJ, Mulhern JG, Braden GL ( 2008) Recognition and management of chronic kidney disease in an elderly ambulatory population. J Gen Intern Med 23(8):1125-1130

5. Foley R, Parfrey P, Sarnak M (1998) Clinical epidemiology of cardiovascular disease in chronic renal disease. Am J Kidney Dis 32(5):S112-S119

6. Go AS, Chertow GM, Fan D, McCulloch CE, Hsu C (2004) Chronic kidney disease and the risks of death, cardiovascular events, and hospitalization. N Engl J Med 351(13):1296-1305

7. Clark LE, Khan I (Jan. 2010) Outcomes in CKD: what we know and what we need to know. Nephron Clin Pract 114(2):c95-102
8. De Nicola L, Minutolo R, Chiodini P, Borrelli S, Zoccali C, Postorino M, Iodice C, Nappi F, Fuiano G, Gallo C, Conte G (Aug. 2012) The effect of increasing age on the prognosis of non-dialysis patients with chronic kidney disease receiving stable nephrology care. Kidney Int 82(4):482-488

9. Green D, Ritchie JP, New DI, Kalra PA (2012) How accurately do nephrologists predict the need for dialysis within one year? Nephron Clin Pract 122(3-4):102-106

10. Glassock RJ, Denic A, Rule AD (2017) The conundrums of chronic kidney disease and aging. J Nephrol 30(4):477-483

11. Gibertoni D, Mandreoli M, Rucci P, Fantini MP, Rigotti A, Scarpioni R, Santoro A (2016) Excess mortality attributable to chronic kidney disease. Results from the PIRP project. J Nephrol 29(5):663-671

12. R Core Team (2018) R: A language and environment for statistical computing. R Foundation for Statistical Computing, Vienna, Austria. https://www.R-project.org/. Accessed 18 July 2018

13. Scrucca L, Santucci A, Aversa F (2007) Competing risk analysis using R: an easy guide for clinicians. Bone Marow Transpl 40:381-387

14. Krolewski AS, Warram JH, Christlieb AR, Busick EJ, Kahn CR (May 1985) The changing natural history of nephropathy in type I diabetes. Am J Med 78(5):785-794

15. Hemmelgarn BR, Zhang J, Manns BJ, Tonelli M, Larsen E, a Ghali W, a Southern D, McLaughlin K, Mortis G, Culleton BF (2006) Progression of kidney dysfunction in the communitydwelling elderly. Kidney Int 69(12):2155-2161

16. Trivedi HS, Pang MMH, Campbell A, Saab P (Apr. 2002) Slowing the progression of chronic renal failure: economic benefits and patients' perspectives. Am J Kidney Dis 39(4):721-729

17. Coresh J, Turin TTC, Matsushita K, Sang Y, Ballew SH, Appel LJ, Arima H, Chadban SJ, Cirillo M, Djurdjev O, Green JA, Heine GH, Inker LA, Irie F, Ishani A, Ix JH, Kovesdy CP, Marks A, Ohkubo T, Shalev V, Shankar A, Wen CP, de Jong PE, Iseki K, Stengel B, Gansevoort RT, Levey AS (2014) Decline in estimated glomerular filtration rate and subsequent risk of endstage renal disease and mortality. JAMA 311(24):2518-2531

18. Wing LMH, Reid CM, Ryan P, Beilin LJ, Brown MA, Jennings GLR, Johnston CI, McNeil JJ, Macdonald GJ, Marley JE (2003) A comparison of outcomes with angiotensin-convertingenzyme inhibitors and diuretics for hypertension in the elderly. N Engl J Med 348(7):583-592

19. Winkelmayer WC, Zhang Z, Shahinfar S, Cooper ME, Avorn J, Brenner BM (2006) Efficacy and safety of angiotensin II receptor blockade in elderly patients with diabetes. Diabetes Care 29(10):2210-2217

20. Kim-Mitsuyama S, Ogawa H, Matsui K, Jinnouchi T, Jinnouchi H, Arakawa K (2013) An angiotensin II receptor blocker-calcium channel blocker combination prevents cardiovascular events in elderly high-risk hypertensive patients with chronic kidney disease better than high-dose angiotensin II receptor blockade alone. Kidney Int 83(1):167-176

21. Turgut F, Balogun Ra, Abdel-Rahman EM (2010) Renin-angiotensin-aldosterone system blockade effects on the kidney in the elderly: benefits and limitations. Clin J Am Soc Nephrol 5:1330-1339

22. Yoon HE, Choi BS (2014) The renin-angiotensin system and aging in the kidney. Korean J Intern Med 29(3):291-295

23. Marcum Z, Fried LF (2011) Aging and antihypertensive medication-related complications in the chronic kidney disease patient. Curr Opin Nephrol Hypertens 20(5):449-456

24. Zachariah D, Brown R, Kanagala P, Bashir a, Mohan M, Callan P, Rajendra R, Clark aL, Squire I, Gunning M, Lang CC, Kalra PR (2013) The impact of age and chronic kidney disease on secondary prevention post primary percutaneous coronary intervention (PPCI). QJM 2013:185-192 
25. Conway B, Webster A, Ramsay G, Morgan N, Neary J, Whitworth C, Harty J (2009) Predicting mortality and uptake of renal replacement therapy in patients with stage 4 chronic kidney disease. Nephrol Dial Transpl 24(6):1930-1937

26. O'Hare AM, Choi AI, Bertenthal D, Bacchetti P, Garg AX, Kaufman JS, Walter LC, Mehta KM, Steinman M, Allon M, McClellan WM, Landefeld CS (2007) Age affects outcomes in chronic kidney disease. J Am Soc Nephrol 18(10):2758-2765

27. Manjunath G, Tighiouart H, Coresh J (2003) Level of kidney function as a risk factor for cardiovascular outcomes in the elderly. Kidney 63:1121-1129
28. Muntner P, Barrett Bowling C, Gao L, Rizk D, Judd S, Tanner RM, McClellan W, Warnock DG (2011) Age-specific association of reduced estimated glomerular filtration rate and albuminuria with all-cause mortality. Clin J Am Soc Nephrol 6(9):2200-2207

29. De Nicola L, Minutolo R, Chiodini P, Borrelli S, Zoccali C, Postorino M, Iodice C, Nappi F, Fuiano G, Gallo C, Conte G (2012) The effect of increasing age on the prognosis of non-dialysis patients with chronic kidney disease receiving stable nephrology care. Kidney Int 82(4):482-488 